\title{
Chronic ILLNESS AND QuALITY OF LIFE
}

\begin{abstract}
The major objective of medical care is to preserve life. If patients cannot be cured and are left with residual chronic diseases then the aim is to provide them with the means to lead a life of quality within the confines of their disease. Rehabilitation in chronic disease means restoring or creating a life of acceptable quality. This is achieved by restoring the patient to optimal physiological and psychological health compatible with the extent of the disease and in doing so improve the quality of life.

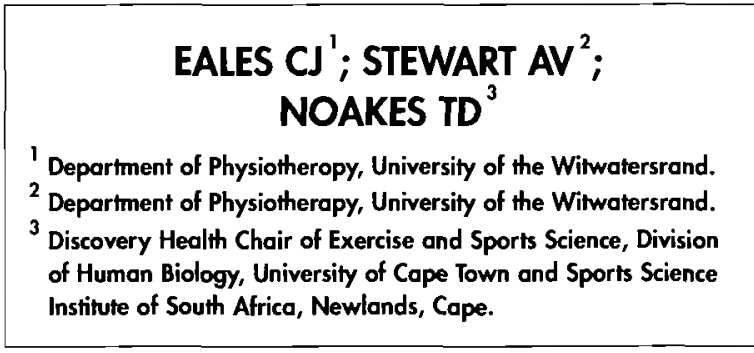
Improved quality of life is the best indicator of successful rehabilitation. Patients with chronic diseases are increasingly expected to become partners when decisions are made regarding their therapy and therefor their evaluation of the outcome is of great importance. There are a number of shortcomings with quality of life evaluations and the most important one is that it does not seem to be adequately defined. Another major problem is that this evaluation usually focuses on aspects of physical function and few studies include subjective indicators. It is generally felt that the opinion of the spouse or caregiver should be included.
\end{abstract}

\section{KEYWORDS: QUALITY OF LIFE, REHABILITATION OUTCOME, CHRONIC ILLNESS, MEASURING HEALTH}

$\mathrm{T}$ The major objective of medical care is to preserve life and to assure its optimal quality. Medical and surgical interventions have become so advanced that mortality rates have decreased significantly and frequently this results in a growing number of patients who must live with chronic illnesses. As there is no cure for a chronic illness, these patients experience a sense of hopelessness and lose confidence (Smith and Nicassio, 1995). In addition depression, disrupted marital and family relationships and decreased ability to work are commonly seen in patients with chronic disease (Kaplan et al, 1987; Smith and Nicassio, 1995). The patient's self-perception is affected by changes in the body and the functional performance of the body. Persistence of medical symptoms leads the patient to the realisation that the medical treatment is limited and as a result medical advice is not accepted with much assurance.

\section{CORRESPONDENCE:}

\section{Eales CJ}

Department of Physiotherapy

Wits Medical School

7 York Road Parktown 2193

Tel: (011) 488-3450

Fax: (011) 488-3210

Email: 159eales@chiron.wits.ac.za
Clinical status has to be set against the background of life and of functioning at home or at work. The knowledge of chronic suffering is much less widespread than the knowledge of acute disease and the result is that the patient's real plight is not fully appreciated, nor understood (WHO, 1980). For these reasons it is important to determine patients' judgement of the medical treatment and the resultant outcome.

With people living longer, the population is increasing and more people are exposed to the development of chronic diseases (Jette, 1993): Chronic disease has superseded acute disease as the major medical problem (Fries, 1980). The practical focus on health improvement over the next decades will be on chronic instead of acute disease, on morbidity and not mortality, on quality of life rather than on duration of life, and on postponement rather than on cure. Because of the complex nature of major diseases, attention is drawn to the factors that influence outcomes, particularly social and psychological outcomes. Outcome is related to choice, assumption of personal responsibility, and education for making decisions about personal health and self-care. Patients should be encouraged to, rather than discouraged from, exercising their personal choice. However returning responsibility to the patient may not be easy to achieve and may cause the patient distress (Fries, 1980).

Health education and preventive medicine can effectively lower the incidence of age-specific chronic disease (Rabbit, 1992) and these two factors should demand the attention of all health care workers. The risk factors for poor health status need to be identified so that health care workers can modify them in order to promote better patient outcomes.

\section{REHABILITATION}

Rehabilitation is defined in the Oxford Dictionary (1992) as: "The process of restoring the individual to effectiveness or normal life by training after illness". This discussion focuses on patients with chronic cardiac disease and rehabilitation is regarded in the broad sense along the lines suggested by the WHO. It includes the total medical care of patients from the time they present for medical care until their final discharge. The WHO defines cardiac rehabilitation as the "sum of activity required to ensure patients the best possible physical, mental and social conditions so that they may regain as normal as possible a place in the community and lead an active and productive life" (WHO, 1964).

Rehabilitation in chronic disease means restoring or creating a life of 
acceptable quality for patients who suffer from chronic diseases. Rehabilitation should not be done "to" people but "with" them. Rehabilitation is an area in which the natural sciences, behavioral sciences and social sciences meet (WHO 1964). In patients with cardiovascular diseases, the WHO Expert Committee on Rehabilitation of Patients with Cardiovascular Diseases was in agreement that every thing possible must be done to rehabilitate such patients in order to restore them to as normal a life as possible in the society in which they live. These patients should be granted the dignity and the right to security in the same way that it is granted to normal individuals and individuals with other major disabilities.

Gordon and Gibbons (1991) stated that "cardiac rehabilitation programs are designed to restore a patient to optimal physiological and psychological health compatible with the extent of the patient's heart problem". The rehabilitative approach should begin at the onset of illness and remain a continuing feature in the long-term care of the patient; however, "the initiation and co-ordination of rehabilitation efforts must be the responsibility of the patient's primary physician..."(Wenger and Hellerstein, 1992).

Therapy for patients with chronic disease is designed to limit the disabling consequences of the illness. Quality of life encompasses the ways in which the patient's life is affected by the illness and by the "components of its care" (Spitzer, 1987). The clinical effectiveness of rehabilitation in chronic diseases, according to Oldridge et al (1991), needs to be judged not only in terms of mortality and morbidity but also in terms of health-related quality of life. Research on the quality of life in the field of rehabilitation has become increasingly popular (Fabian, 1991)

The measurement of outcome of treatment for the patient is the keystone of modern medicine, and its importance is being recognised throughout clinical practice. This is especially the case when costly invasive treatments are involved. Survival figures, clinical judgement of outcome, return to work and test results have been the prevalent methods of assessing outcome. The main reason for their use may be that they are easier to measure (Caine et al, 1991). For instance it could be that return to work is more closely related to personality type and that the patient may want to work, but if the financial circumstances of the patient permitted, then not to return to work may in fact have improved the patient's quality of life to a greater extent. There has been a change of emphasis in the assessment of patients with chronic disease recently and the trend is more towards assessing outcome in terms of patients' perceptions of changes in their state of health over a period of time.

\section{REHABILITATION AND QUALITY OF LIFE}

The traditional and accepted definition of rehabilitation is that it is the reduction of disability and handicap with or without a change in the underlying impairment. These changes are not unrelated to the individuals in whom they occur although not much attention has been given to the reaction of the patient to them. The effects of the disease process can never be partitioned between body and mind (WHO, 1980). Rehabilitation means a goal directed and time limited process aimed at enabling an impaired person to reach an optimum mental, physical and/or social functional level, thus providing him or her with the tools to change his or her own life. It can involve measures to compensate for a loss of function or a functional limitation (for example technical aids) and other measures intended to facilitate social adjustment or readjustment (United Nations, 1983).

For the purpose of this paper, patients with cardiac disease will be considered as examples of patients with chronic disease. In patients with cardiac disease, the reduction of disability and handicap are considered more appropriate determinants of outcome than is a reduction in mortality or morbidity. There is also consensus that criteria such as function in daily life, productivity, emotional stability and life satisfaction can be considered as indicative of the improved quality of life of the patient (Wenger et al, 1984). In coronary artery disease the impairment is coronary atherosclerosis, the disability is the presence of angina and the handicap is the inability to function normally in the community. The presence of these factors leads to a poor quality of life (Oldridge, 1986). A common interpretation of rehabilitation for patients with cardiac disease is that they should be "restored and maintained" at optimal clinical, social, vocational and psychological status. This implies that all this would be done for the patient, possibly by a health professional, and that the role of the patient would be passive.

The definition of the WHO is slightly different and implies that the patient should assume some responsibility for their rehabilitation in the process of regaining as normal as possible a place in the community (WHO, 1964). Perhaps health care workers need to look at their perspectives on rehabilitation and consider five important conceptual changes that are suggested by Sartorius (1992).

The first concept is the improvement of overall quality of life as perceived by the patient as well as the patient's family. Secondly, if the quality of life is to become a criterion for assessing improved rehabilitation, the opinion of those whose life is being changed must become a decisive factor, rather than using this as an interesting point of observation. A third important point is that people are different and so are impaired people, and rehabilitation workers should be tolerant to these differences. The outcome of rehabilitation should not be judged by the patient's ability to abide by rigid, predetermined rules of "normal" behaviour. Being able to find a job is still considered confirmation of a patient's worth with the result that activities such as help and support to others, the upbringing of children and creative art, are given much less attention and respect than the ability to function in a traditional job.

Fourthly it must be borne in mind that people and impairments change over time. These changes, as well as the changes in the world in which patients live, should be respected. It has to be appreciated that rehabilitation is a longlasting process and people must be accommodated as they move forward in this process. Rules and judgements will have to keep changing while all are 
moving forward in time. Fifthly, as we come to understand more fully that rehabilitation is an intervention to improve the quality of life, so it becomes important to appreciate that there is not a strict distinction between services dealing in rehabilitation and those that aim to help people in other ways. This connection does not only imply the differences between health and rehabilitation services but also between these services and other community services. The result will be unity of purpose and aim and a higher priority for rehabilitation. Improving the patient's quality of life will include certain factors that are important to all of us and certain factors that are important specifically to the patient (Cohen, 1982).

\section{QUALITY OF LIFE AS A HEALTH CARE ISSUE}

The aim of medical intervention is primarily to maintain life. However, through the ages, health care workers have always sought much more for their patients than merely a prolongation of life. If the "good life" of the patient is the aim of the medical team, it is essential that not only should the prolongation of life be considered but in addition, the quality of that life. Philosophers as far back as Socrates have emphasised this point. It was Socrates who said in an Athenian court that he feared some things more than death and that it was not merely the possession of life itself, but the quality of that life, that counts most (Cohen, 1982). Therefor the major objective of medical care is to preserve life and to assure its optimal quality.

An argument has been put forward that a human person is a life lived according to a human plan (Royce, 1908). Diseases are not always fatal but the patient's comfort and happiness is affected by them and as a result a patient can no longer lead life according to his/her plan (Mosteller et al, 1980) and thus the quality of life of the patient is affected. The objectives of the rehabilitation team should be to assist the patient in reformulating their life-plan in order to lead a life with some quality.

In the final outcome the quality of life of the patient may be affected. For this reason it becomes important to assess the patient's judgement of the medical treatment and the resultant outcome. Chronic diseases of the later years are often responsible for most premature deaths (Fries, 1980). Quality of life measures are important to determine the impact of chronic diseases on patients' lives (Guyatt et al, 1993).

The challenge of ascertaining quality of life as an outcome of rehabilitative care lies in the assumption that the bulk of medical and surgical treatment is not life saving but on the contrary aimed at improving the state or quality of life. Patients are increasingly expected to become partners when decisions are made regarding their therapy. In order for them to make informed decisions, information on how treatment will affect their lives, is important (Kinney et al, 1996).

To determine whether an intervention has been successful it is essential that the improvement of the medical status of the patient as well as the patient's perception of this outcome be considered, in other words the quality of life of the patient must be assessed.

Moving away from an emphasis on mortality, health researchers are now focusing more on the causes and consequences of disability. The evaluation of the quality of life provides much greater understanding of the impact and treatment of the illness than traditional outcome measures (Ferrans, 1990).

\section{DEFINING QUALITY OF LIFE}

One of the major problems with quality of life research is that there is no universal definition of quality of life. Failure to define quality of life has been identified as a major weakness in many studies (Kinney et al, 1996). It has been reported that in only $15 \%$ of the literature the concept "quality of life" was actually defined (Gill and Feinstein, 1994). Without defining quality of life there is no blueprint for the measurements taken to support the definition. Knapp and McClure (1978) regard quality of life as a multidimensional concept that can be viewed as a transaction between individuals and their social and physical environment. Personality traits such as "expectancy of success", adaptability and competence are some of the individual differences observed in patients' attempts to master their environment.
Quality of life is a dynamic construct and one should bear in mind that attitudes are not constant and are continually modified by phenomena such as adaptation, coping and self-control. Individuals also change the standards by which they assess quality of life during a prolonged disease process and this can become an important factor when measuring outcome (Allison et al, 1997).

Analysis of the literature resulted in identifying two important factors affecting an individual's quality of life. These two factors are the health of the patient and the ability to achieve and maintain maximal functional independence and autonomy (King et al, 1992; Williams, 1994). Lamendola and Pelligrini (1979) described quality of life as a complex concept used by patients to subjectively assess the desirability of a particular way of life. The quality of that way of life is the satisfaction it provides the individual (Ferrans and Powers, 1992).

According to Flanagan (1982) health and subjective well being are of central importance in the assessment of quality of life. Health includes the objective evaluation of disease and the patient's perception of symptoms. Subjective well being includes measures such as the patient's assessment of life in terms of happiness, life satisfaction and positive effects. Health has been reported as the most important aspect of happiness (Campbell, 1970).

Palmore and Luikart (1972) stated that self-rated health was the predominant variable to influence life satisfaction. However, it is important to note that the relationship between satisfaction with health and well being is only moderate. It seems that the influence of health on well being does not merely reflect how people feel physically, but to some extent what their health allows them to do in terms of functional capacity. Note has to be taken of the suggestions by Wiklund et al (1987) that subjective measures of health are more strongly related to happiness (satisfaction) and that objective measures have only a limited relationship to subjective assessments. It is therefore essential to include both kinds of indicators when measuring health. 
Happiness is associated with the good life. Happiness for Aristotle stemmed from virtuous activity of the soul throughout a complete life, with external goods adding luster to it (Aristotle: Ethica nicomachea, 1947). Happiness and satisfaction are not synonyms and behave differently across the life span of the general population. Happiness decreases with age whereas satisfaction increases. Happiness suggests short-term positive feelings whereas satisfaction implies longer-term cognitive experience resulting from a judgement of life's conditions (Patrick and Erickson, 1993).

Campbell (1993) states that there is no doubt that happiness and satisfaction have something in common but there is also a difference. Satisfaction in his view involves an act of judgement, whereas happiness is characterised by a spontaneous "lift-of-the-spirits". For this reason it is argued that satisfaction comes closer to capturing the concept of quality of life than does happiness (Ferrans, 1990). Along with life satisfaction and happiness as indicators of psychological well-being, perceptions of physical well-being are also important, particularly when assessing quality of life of individuals who have experienced disruption in their physical health status (Packa, 1989; King et al, 1992).

A simple but astute definition of quality of life is offered by Ory et al (1994). They define quality of life as a "multidimensional concept that refers to an individual's overall life satisfaction and total well-being". They go on to say that the most important factors that affect the patient's quality of life are the patient's health and ability to function. The aim of medical intervention should be to obtain optimal function and to decrease disability and thereby increase healthrelated quality of life. Quality of life has become an increasingly important measure to assess the impact of disease and the outcome of treatment on individuals and their families.

The domains (areas, fields) commonly thought to comprise health-related quality of life and considered important by Ory et al (1994) are: physical health, functional ability, emotional health (depression, anger, anxiety and perceived stress), sexual functioning, work productivity, social performance and life satisfaction.

Quality of life is a particularly relevant outcome in cardiac rehabilitation in that it also reflects the patient's personal value system, life satisfaction and judgements on perceived health status. Perceived health status in turn has been demonstrated to correlate better with mortality risk than many other objective measures (Kaplan and Camacho, 1983).

Health is one of the most important components of quality of life (Cleary et al, 1991). The term "health-related quality of life " refers to physical, psychological and social domains of health, seen as distinct areas that are influenced by a person's experiences, beliefs, expectations and perceptions.

Each of these domains can be measured in two dimensions: 1) objective assessments of functioning or health status and 2) subjective perceptions of health. Although the objective dimension is important in defining a patient's degree of health, the patient's subjective perceptions and experiences translate the objective assessment into the actual quality of life experienced. When a patient becomes ill almost all aspects of life become health related (Guyatt et al, 1986).

The patient's own value system is important in assessing quality of life. There is growing consensus that the individual himself is the only proper judge of his/her quality of life (Guyatt et al, 1986; Ferrans, 1990; Denollet, 1994) and it has been postulated that self-rated health is the predominant variable to influence satisfaction with life in middle age (Palmore and Luikart, 1972). Quality of life is a reflection of the way a person feels and functions (Guyatt et al, 1986). Clinicians tend to overestimate the role of life skills and to underestimate the role of social needs. The term "quality" simply implies an evaluation or subjective rating by the individual. The subjective ratings can be of life in general or various components of life such as social life, financial situation or work (Stewart and King, 1994). Subjective states are difficult to measure and thus investigators tend to bypass personal evaluations and infer quality of life through knowledge of aspects of the individual's behaviour that can be observed and measured.

Presuming subjective quality of life or well being from external circumstances does not fully take into account the values, needs and adaptability of individuals to various life situations (Flanagan, 1982).

The spouse's evaluation in the assessment of the patient's quality of life is important. It has been suggested by some researchers that the opinion of the spouse or caregiver should be included in quality of life assessments (Wenger et al, 1984; Kinney et al, 1996). The patient's opinion of his/her quality of life is considered to be the only true reflection of that particular life experience. The opinion of the spouse/caregiver is also of importance because the reliability of assessments is increased by another respondent's perspective. The patient also does not usually live in isolation and therefore the way they perceive their life experiences, will be reflected by those around them. Mayou and Bryant (1993) however feel that there may be a problem with disagreements and that it is best to consider only the opinion of the patient. However, to lose the information on how the intervention affects the family, would result in an incomplete evaluation, and in spite of the possibility of disagreement it would be desirable to include the spouse/caregiver.

\section{THE DOMAINS THAT CONSTITUTE QUALITY OF LIFE:}

According to Gill and Feinstein (1994) the domains under investigation in quality of life research are frequently not identified (identified only in $47 \%$ of cases). There is as yet no universal definition of quality of life but it is generally felt that quality of life can be represented by four important areas (domains) [Kinney et al, 1996]

- Symptoms and side effects

- Physical function

- Social function

- Psychological status

Although Kinney et al (1996) feel that these domains fully represent quality of life the authors are of the opinion that these domains are incomplete because information is lacking on sexual activity, 
cognitive functioning, and life satisfaction. There is also too little emphasis of the patient's own perception of his/ her health and therefore the suggested definition by Ory et al (1994) is more inclusive.

According to Stewart and Ware (1992) the domains commonly thought to comprise health related quality of life are: physical health, emotional health, cognitive functioning, sexual functioning, social role performance, work productivity, and life satisfaction.

These domains correlate well with those described by Ory (1994) except for cognitive functioning, and they cover all areas that are essential for the evaluation of quality of life. The cognitive function of the patient is said not to be affected by bypass surgery (Klonoff et al, 1989) and therefore it is suggested that the most relevant and acceptable domains are those described by Ory (1994). They are physical health, functional ability, emotional health (depression, anger, anxiety and perceived stress), sexual functioning, work productivity and social performance and life satisfaction.

Quality of life as a dynamic construct is frequently ignored in medical research. When assessing quality of life it is assumed that the point of reference does not change, meaning that an individual's attitude towards a certain construct (concept) remains the same. However, it is important to bear in mind that attitudes are not constant and are constantly modified by phenomena such as adaptation, coping and self-control. Researchers in quality of life issues have recognised between-subject differences when determining the content of the measuring instrument. However, according to Allison et al (1997), within-subject differences (i.e. the fact that the individual changes the standards by which he/she assesses his/her quality of life) have been largely ignored.

To explain the foregoing statement consider the following: In a study on transplant recipients and haemodialysis patients by Evans (1991) he reported that these patients were often happier, more satisfied and reported a better quality of life than healthy patients. The standard by which these patients assessed their quality of life was different from the "normal" population because of a process of adaptation, coping and self-control.

A possible way to overcome this problem when researching quality of life is to compare the post intervention measurement with reference to the pre-intervention measurement e.g. Are you as active (functional) as before the operation?

The use of individualised questionnaires should also be considered. Patients should be given the opportunity to decide for themselves which aspects of their lives they value more (weigh the importance of the domains) but not actually choose the questions themselves. Patients may decide that their social function is more important than their physical function. However, the researcher should still design the questions to determine social and physical function.

Finally, pre-intervention characteristics should be evaluated. In 1982, Cohen suggested that patients' "lifeplans" in terms of their goals and hopes should be taken into account when considering quality of life and also whether interventions resulted in the fulfillment of their "life-plan" or resulted in frustration. This would be difficult because phenomena such as coping strategies, adaptation, expectations and optimism would then be ignored. Goodinson and Singleton (1989) have suggested that the information appropriate to a patient's improved quality of life can not be separated from coping strategies and past experiences of illness. If these characteristics could be determined before the intervention the data obtained would not be compromised due to their temperament or attitude.

\section{SHORTCOMINGS OF QUALITY OF LIFE MEASUREMENTS}

It is no longer adequate to demonstrate that medical interventions result in physiological changes unless an accompanying change in life function can also be demonstrated (Lomas et al; 1987). It seems that quality of life measures that have relied on clinical judgement alone, may have inadequately represented patient values.
Frequently the focus was on objective measures and not on subjective indicators of quality of life (O'Young and McPeek, 1987) and these measures were taken only as a single evaluation (Hollandsworth, 1988).

There is widespread scepticism whether quality of life can be measured in any meaningful manner because of inadequate measures used to assess the impact of cardiac disease and its treatment on the lives of patients. However, methods are constantly improving and there are a number of standard measures of quality of life available making quality of life assessments possible and worthwhile (Mayou and Bryant, 1993). The relevance of quality of life measures is frequently not explained to the practising clinician. The principal goal of clinical care is to improve patient outcomes. In order for physicians to embrace the concept of measuring health related quality of life the validity of these measures must be proved and it must be clear to them how they will be able to use this data (Wilson and Cleary, 1995).

An interesting opinion expressed by Gill and Feinstein (1994) is that, because quality of life is such an "uniquely, personal perception", it can be measured only by determining the opinions of patients and supplementing existing methods.

Any assessment instrument should allow patients to add additional items they consider important which may not have been included in the questionnaire (Gill and Feinstein, 1994).

A summary of the shortcomings of improved quality of life measures

- Quality of life is not adequately defined.

- The focus is mainly on physical function, symptoms and side effects.

- Measurements are taken at one point in time only

- There is no evidence of the validity, reliability or sensitivity of existing measures to detect change

- The relevance of the findings for the clinician is not indicated

- There is usually no opportunity for patients to add on to the measuring instrument, items that they consider important.

- The domains are not clearly defined 


\section{IMPORTANT INFORMATION GAINED FROM PREVIOUS STUDIES}

1. Few studies included subjective indicators of quality of life and that many focused on objective indicators only ( O'Young and McPeek, 1987).

2. There is a tendency to rely on one time evaluations only (Hollandsworth, 1988).

3 . The opinion of the spouse or caregiver should be included in quality of life assessments (Wenger, 1984; Kinney et al, 1996). The patient's opinion of his/her quality of life is the only true reflection of that particular life experience but the opinion of the spouse/caregiver is also of importance because the reliability of assessments is increased by another respondent's perspective.

There is ample evidence in the literature that successful outcome of a medical or rehabilitation intervention should be measured in terms of an improvement in quality of life. The above three points confirm the importance of self reported improved quality of life and that no measure of quality of life is adequate if it does not include the patient's own perceptions.

\section{REFERENCES}

Allison PJ, Locker D, Feine JS 1997 Quality of life: a dynamic construct. Social Science Medicine 45:221-230

Aristotle: Ethica nichomacea, in McKeon $\mathbf{R}$ (ed): Introduction to Aristotle. New York, NY, Modern Library, 1947 pages 300-543

Caine N, Harrison SCW, Sharples LD, Wallwork J 1991 Prospective study of quality of life before and after coronary artery bypass grafting. British Medical Journal 302: 511-516

Campbell A 1993 Concepts of health related quality of life. In: Health Status and Health Policy. Allocating resources to Health Care. Patrick DL, Erickson P 1993 Oxford University Press Inc. pp 100-104

Campbell A. 1970 Subjective measures of well-being. American Psychologist 31: 117 - 124

Cleary PD, Greenfield S, McNeil BJ. 1991 Assessing quality of life after surgery Controlled Clinical Trials 12:189S-203S .
Cohen C 1982 On the Quality of Life: Some Philosphical Reflections.Circulation 66 (suppl 111): 111-29-111-33

Denollet J 1994 Health complaints and outcome assessment in coronary heart disease. Psychosomatic Medicine 56: 463 - 474

Evans RW 1991 Quality of life. Lancet 338: 636

Fabian E S 1991 Using Quality-of-life indicators in rehabilitation program evaluation. Rehabilitation Counselling Bulletin 34: 344 356

Ferrans CE, Powers M 1992 Psychometric assessment of the quality of life index. Research in Nursing and Health 15: $29-38$

Ferrans CE 1990 Quality of Life: Conceptual Issues. Seminars in Oncology Nursing 6(4): 248-254

Flanagan JC 1982 Measurement of quality of life: current state of the art. Archives of Physical and Medical Rehabilitation 63:56-59

Fries JF 1980 Ageing, Natural Death, and the Compression of Morbidity. New England Journal of Medicine 303(3): 130-135

Gill TM, Feinstein AR 1994 A critical appraisal of the quality of quality-of-life measurements. Journal of the American Medical Association 272: 619-626

Goodinson SM, Singleton J 1989 Quality of life: a critical review of current concepts, measures and their clinical implications. International Journal of Nursing Studies 26:327-341

Gordon N, Gibbons L 1991 The complete heart recovery guide. Oxford University Press, Cape Town pp 205-211

Guyatt G, Crowe J, McKelvie R, Runions J, Oldridge NB 1986 Assessing Quality of life in cardiovascular disease: A general approach and an example in patients with myocardial infarction. Quality of Life in Cardiovascular Care 83:304-318

Guyatt GH, Feeney DH, Patrick DL 1993 Measuring health-related quality of life. Annals of Internal Medicine 118: 622-629

Hollandsworth JG 1988 Evaluating the impact of medical treatment on the quality of life: A 5-year update. Social Science and Medicine 26: $425-434$

Jette A M 1993 Using health-related quality of life measures in physical therapy outçomes research. Physical Therapy 73: $528-537$
Kaplan GA, Camacho TC 1983 Perceived health and mortality: A nine year follow-up of the human population laboratory cohort. American Journal of Epidemiology 117: 292

King KB, Porter LA, Norsen LH, Reis HT 1992 Patient perception of life after coronary artery surgery: Was it worth it? Research in Nursing and Health 15:327-334

Kinney MR, Burfitt SN, Stullenbarger E, Rees B, DeBolt MR 1996 Quality of life in cardiac patient research: A meta-analysis. Nursing Research. 45:173-180

Klonoff H, Clark C, Kavanagh-Gray D, Mizgala H, Munro 11989 Two year follow-up study of coronary bypass surgery. Physiologic status, employment status, and quality of life. Journal of Cardiovascular Surgery 97:78-85

Knapp F jr, McClure L F 1978 Quasi-experimental evaluation of a quality of life intervention. Journal of Community Psychology 6: $280-290$

Lamendola WF, Pelligrini RV 1979 Quality of life and coronary artery bypass patients. Social Science of Medicine 134: 457-461

Lomas J, Pickard L, Mohide A 1987 Patient versus clinical item generation for quality-oflife measures. Medical Care 25: 764 - 769

Mayou R, Bryant B 1993 Quality of life in cardiovascular disease: Position paper. British Heart Journal 69: 460 - 466

Mosteller F, Gilbert JP, Mcpeek B 1980 Reporting standards and research strategies for controlled trials. Controlled Clinical Trials 1: 37

O'Young J, McPeek BC. 1987 Quality of life in surgical trials. Journal of Chronic Disease 40: $513-522$

Oldridge N B 1986 Cardiac Rehabilitation, Self-responsibility, and Quality of Life. Journal of Cardiopulmonary Rehabilitation 6: $153-156$

Oldridge N, Guyatt G, Jones N, Crowe J, Singer J, Feeny D, McKelvie R, Runions J, Streiner D, Torrance G 1991 Effects on quality of life with comprehensive rehabilitation after acute myocardial infarction. The American Journal of Cardiology 67: $1084-1089$

Ory MG, Cox DM, Gift HC, Abeles RP. 1994 Ageing and quality of life: Celebrating new research discoveries. In: Abeles RP, Gift HC, Ory MG (eds) Ageing and Quality of Life. Springer Publishing Company Inc. Broadway, New York

Oxford Dictionary 1992 
Packa DR 1989 Quality of life of cardiac patients: A review. Journal of Cardiovascular Nursing 3: $1-11$

Palmore E, Luikart C 1972 Health and social factors related to life satisfaction. Journal of Health and Social Behavior I3: $68-80$

Patrick DL, Erickson L. 1993 Health Status and Health Policy. Quality of life in health care evaluation and resource allocation. Oxford University Press New York pp76-112

Rabbitt P 1992 Ageing gracefully. The Lancet 339 (9): 1157 - 1158

Royce J 1908 The philosophy of loyalty lecture IV section 4. In: Cohen C 1982 On the quality of life: some philosophical reflections. Circulation 66(suppl. III): 29 - 33

Sartorius N 1992 Rehabilitation and Quality of Life. Hospital and Community Psychiatry 43:1180 - 1181

Smith T W, Nicassio P M Psychological practice: clinical application of the biopsychosocial model ppl - 31. In: Nicassio P M, Smith T W (eds) 1995 Managing chronic illness: a biopsychosocial perspective. American Psychological Association. Washington. DC
Spitzer W O 1986 Sate of science: Quality of life and functional status as target variables for research - Key note address. Journal of Chronic Diseases 40: 465

Stewart AL, King AC 1994 Conceptualizing and measuring quality of life in older populations. In: Abeles RP, Gift HC, Ory MG (eds) Ageing and quality of life. Springer Publishing Company Inc. Broadway, New York

Stewart A L, Sherbourne C D, Hays R D, Wells K B, Nelson E C, Kamberg C J , Rogers W H, Berry S D, Ware J E In: Stewart A L, Ware J E (eds) 1992 Measuring functioning and well-being: the medical outcomes study approach. Duke University Press, Durham N C

United Nations 1983 World programme of action concerning disabled persons. United Nations Canada

Wenger $\mathrm{N} \mathrm{K}$, Hellerstein $\mathrm{H} \mathrm{K}$ Preface to the first addition ppXV. In: Wenger $\mathrm{N} \mathrm{K}$, Hellerstein H K (eds) 1992 Rehabilitation of the Coronary Patient (third edition). Churchill Livingstone, New York

Wenger NK, Mattson ME, Turberg CD, Elinson J 1984 Assessment of Quality of Life in Clinical Trails of Cardiovascular Therapies.
The American Journal of Cardiology 54: 908-913

Wiklund I, Lindvall K, Swedberg K, Zupkis RV 1987 Self-assessment of quality of life in severe heart failure. Scandanavian Journal of Psychology 28: 220-225

Williams FT 1994 Rehabilitation in old age. In: Abeles RP, Gift HC Ory MG 1994 Ageing and Quality of Life. Springer Publishing Company Inc. Broadway, New York. Pp 121132

Wilson I B, Clearly P D 1995 Linking clinical variables with health-related quality of life. A conceptual model of patient outcomes. Journal of the American Medical Association 273: $59-65$

World Health Organization 1964 Rehabilitation of patients with cardiovascular diseases: report of a WHO Expert Committee. Geneva

World Health Organization 1980 International Classification of Impairments, Disabilities, and Handicaps. Geneva

\section{Pilates training Course \& Equipment}

Two week Full-time course:

- Supervised Pilates workouts

- Observation

- Practical teaching

- $\quad$ Assisted teaching

- Lecture, theory \&application

Weekend workshops

- Offering clinical Pilates for physiotherapists \&

New York Pilates all levels.

Certification offered.

Natasha Madel, Studio Director \& the only certified Pilates instructor in South Africa, who has received her certification from Romana Kryzanowska. Romana Kryzanowska was a disciple of Joseph Pilates \& is a director of the Pilates studio teacher training program in New York.

The Pilates Method.is a series of exercises developed over seventy years ago by legendary physical, trainer Joseph Pilates. His unique practiced movements are, designed to stretch and tone your muscles while eliminating tension and strain from your joints. Learn how to isolate muscles \& fine tume movements, encouraging the body to reach its full potential

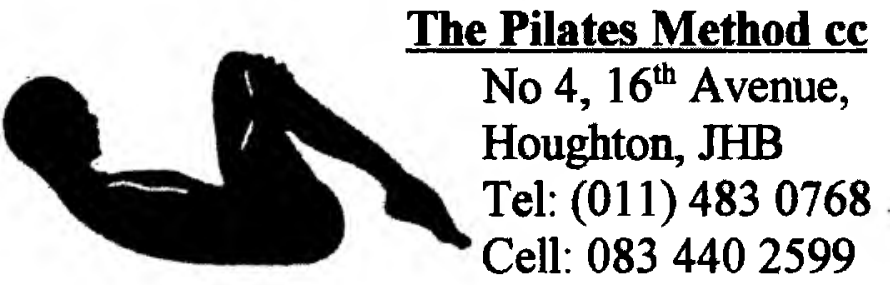

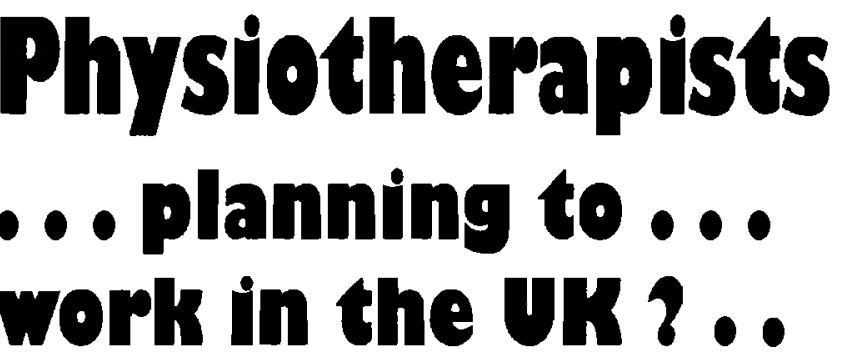

We will help you make a positive choice of Physiotherapy locum or permanent positions. CMS offer a personal and professional service accompanied by a full and comprehensive range of benefits with particular emphasis on providing you with continual support whilst you are working in the UK.

\section{contact Cecily Smyth BSc. OT}

our S.A. Consultant in Jo'burg

email: cecilysmyth@visto.com

telffax: $\quad$ (II) 7021375

(or visit our website) www.countrywidemedical.co,uk

COUNTRYWIDE MEDICAL SELECTION

Eastgate House, Eastgate Streec, Winchester,

Hampshire SO23 8DZ England

Tel: $\quad$ +Toll Free 0800999148

Fax.

$+441962865654$

Email: cms@cms-Itd.co.uk 